\title{
OS PAPÉIS DOS ESPAÇOS LIVRES PÚBLICOS NA ESTRUTURAÇÃO TERRITORIAL E NO PROJETO DE PARCELAMENTO: A EXPERIÊNCIA DE ENSINO NA PUC-CAMPINAS
}

\author{
THE FUNCTIONS OF PUBLIC SPACES AT TERRITORIAL STRUCTURE AND PARCELING \\ PROJECT: THE METHOD OF EDUCATION EXPERIENCED AT PUC-CAMPINAS
}

\author{
Jonathas Magalhães Pereira da Silva* \\ Denio Benfatti** \\ Tomás Antonio Moreira*** \\ Caroline Krobath Luz Pera****
}

\section{RESUMO}

Considerando as práticas contemporâneas de ensino no Projeto e no Planejamento Urbano e Regional, o presente texto objetiva compartilhar a experiência de ensino desenvolvida nos anos de 2009 a 2012 na FAU/PUC-Campinas. Apresentam-se os procedimentos e posturas atitudinais adotadas em sala de aula, explicitando as etapas de desenvolvimento, os argumentos e os resultados obtidos. Por meio da sistematização da experiência pedagógica, objetiva-se a construção de um diálogo interdisciplinar que explicite avanços na consideração dos sistemas de espaços livres de edificação no processo de planejamento e estruturação territorial. Busca-se com o exercício proposto identificar e questionar os processos contemporâneos de ocupação territorial condicionados por uma lógica em que o transporte individual é dominante e pela ausência de uma estruturação territorial prévia aos projetos de parcelamento de solo. A disciplina não quer se limitar a instrumentalizar o aluno para a prática profissional, mas sim provocar uma prática reflexiva baseada na construção de argumentos que se revelem em desenhos, considerando as diferentes escalas, os interesses de diferentes agentes, as contradições existentes e a história da disciplina. $O$ desenho da paisagem é utilizado aqui como instrumento de reflexão que contesta a realidade e cria argumentos para novas configurações espaciais urbanas.

Palavras-chave: Paisagismo. Ensino. Sistema de espaços livres. Planejamento urbano e regional.

* Professor doutor do Programa de Pós-Graduação em Urbanismo (POSURB) da Faculdade de Arquitetura e Urbanismo da Pontifícia Universidade Católica de Campinas (FAU/PUC-Campinas). Rodovia Dom Pedro I, km 136, Parque das Universidades, 13086-900, Campinas, SP, Brasil. jonathas.silva@puc-campinas.edu.br

** Professor doutor do Programa de Pós-Graduação em Urbanismo (POSURB) da Faculdade de Arquitetura e Urbanismo da Pontifícia Universidade Católica de Campinas (FAU/PUC-Campinas). Rodovia Dom Pedro I, km 136, Parque das Universidades, 13086-900, Campinas, SP, Brasil. deniobenfatti@puc-campinas.edu.br

*** Professor doutor do Programa de Pós-Graduação em Urbanismo (POSURB) da Faculdade de Arquitetura e Urbanismo da Pontifícia Universidade Católica de Campinas (FAU/PUC-Campinas). Rodovia Dom Pedro I, km 136, Parque das Universidades, 13086-900, Campinas, SP, Brasil. tomas.moreira@puc-campinas.edu.br

**** Arquiteta pela Faculdade de Arquitetura e Urbanismo da Pontifícia Universidade Católica de Campinas (FAU/PUC-Campinas). Mestranda do Programa de Pós-Graduação em Urbanismo (POSURB/ PUC-Campinas). Rodovia Dom Pedro I, km 136, Parque das Universidades, 13086 900, Campinas, SP, Brasil. carolinepera@gmail.com 


\begin{abstract}
Considering the contemporary practices of teaching in Project and in Urban and Regional Planning this text aims to share the teaching experience developed between 2009 and 2012 at FAU PUC-Campinas. The article presents the procedures and attitudinal postures adopted in the classroom detailing the development stages, the arguments and results. The text search, through the teaching experience systematization, the construction of an interdisciplinary dialogue which sets out clearly the progress when the open spaces system is considered in the territorial planning process. The proposed exercise aims to question the contemporary territorial processes occupation conditioned by a logic where the individual transport is dominant and the absence of a territorial structuring. The discipline is not to be limited to exploit for professional practice, but provoke a reflective practice based on the construction of arguments that reveal themselves in drawings considering the different scales, the interests of different actors, the contradictions and the history of the discipline. The landscape design is used here as an instrument of reflection that contests the reality and creates arguments for new urban spatial configurations.
\end{abstract}

Keywords: Landscaping. Education. Open system spaces. Urban and regional planning.

\title{
1 INTRODUÇÃO
}

Os avanços disciplinares das ciências não trouxeram apenas as vantagens da divisão do trabalho, trouxeram o inconveniente da hiperespecialização, do parcelamento e da fragmentação do saber. Este tornou-se mais esotérico (acessível apenas aos especialistas) e anônimo (concentrados em bancos de dados e utilizados por instâncias anônimas, a começar pelo Estado). [...] Nessas condições, o cidadão perde o direito ao conhecimento. Tem o direito de adquirir saber especializado ao fazer estudos ad hoc, mas é despojado na qualidade de cidadão, de qualquer ponto de vista global e pertinente.

Edgar Morin - 2002

A reflexão a respeito dos conteúdos de uma disciplina revela a sua história e passa pelo desafio de propor conteúdos que garantam a formação do cidadão e do profissional com habilidades e competências específicas. No presente texto, busca-se uma relação interdisciplinar entre Planejamento, Urbanismo e Paisagismo, assim como se reconhece que a construção desse conhecimento depende da investigação de diversos aspectos socioeconômicos intimamente ligados à produção do espaço urbano.

É certo que os corpos docentes das faculdades de Arquitetura e Urbanismo se mantêm, atualmente, afastados em relação às teorias da educação, sendo elas muito pouco exploradas, ou até mesmo esquecidas. Porém a formação docente não está contida em procedimentos preestabelecidos e, portanto, não será possível reduzir esse processo a algumas horas de um curso que, supostamente, estaria formando docentes capacitados. (SILVA, 2005). O avanço do processo pedagógico depende do constante questionamento sobre o conteúdo e a forma que se utiliza para transmiti-lo.

Acredita-se que a formação docente só é possível em um processo de pesquisa no qual se faça uma reflexão sobre os conteúdos da disciplina e se desenvolva, junto às teorias da educação, métodos de transmitir esses conhecimentos. Entende-se que o processo de aquisição de conhecimento ocorre, em parte, por meio de pesquisas que colaboram na formação de quadros e conteúdos, assim como pela reflexão sobre as atividades práticas relacionadas à pesquisa e à atuação profissional. (SILVA, 2005). 
O presente artigo expõe a preocupação e o esforço de seus autores em explicitar o método utilizado para a construção do conhecimento na disciplina Planejamento Urbano e Regional A na Pontifícia Universidade Católica de São Paulo (PUC-Campinas), considerando a regulamentação profissional existente hoje no Brasil. A universidade tem obrigação de questionar e identificar conteúdos mínimos condizentes com as atribuições e responsabilidades concedidas ao profissional de arquitetura e urbanismo.

Para avançar nas discussões, tomam-se os conceitos de César Coll, segundo o qual os conteúdos de uma disciplina são compostos de: definição de conceitos, procedimentos e atitudes (COLL, 1998). Dessa forma, mais do que sobre um conteúdo prescritivo, pretende-se aqui refletir sobre quais são os conhecimentos fundamentais para a formação do aluno de arquitetura e urbanismo, que, em sua prática profissional, terá que enfrentar contradições e conflitos do espaço urbano e rural.

Segundo Hughes (apud Schön, 2000), pioneiro da sociologia das profissões, o ensino estabelece uma barganha com a sociedade: em troca do acesso ao conhecimento, a sociedade confere um mandato para o controle social de seu campo de especialização e uma licença para determinar quem deve ser investido da autoridade profissional. Porém essa barganha não está mais funcionando. Conforme Schön (2000, p. 18):

Quando os profissionais não são capazes de reconhecer ou de responder conflitos de valores, quando violam seus próprios padrões éticos, quando ficam aquém de expectativas criadas por eles próprios a respeito de seu desempenho como especialista ou parecem cegos para problemas públicos que eles ajudaram a criar, são cada vez mais sujeitos a expressões de desaprovação e insatisfação. Críticos radicais, como lvan Illich (1970), os condenam por apropriação indevida e monopólio do conhecimento por simplesmente ignorar as injustiças sociais. Os próprios profissionais argumentam que é impossível corresponder a expectativas elevadas da sociedade com relação ao seu desempenho, em um ambiente que combina uma turbulência crescente com a regulamentação cada vez maior da atividade profissional. [...] Apesar dessas diferentes ênfases, críticos profissionais, públicos e radicais fazem uma reclamação em comum: as áreas mais importantes da prática profissional encontram-se, agora, além das fronteiras convencionais da competência profissional.

É fato que o arquiteto urbanista recém-formado não detém TODAS as habilidades necessárias para atender de imediato o mercado de trabalho. As habilidades serão certamente construídas com a vivência profissional, se a aquisição da base de conhecimentos necessários for garantida na graduação. Cabe à universidade definir e garantir essa base de conhecimento.

Um avanço importante ocorrev em 1994, quando se estabeleceu a obrigatoriedade da disciplina de Paisagismo. A partir dessa decisão, inicia-se uma discussão em âmbito nacional sobre seus conteúdos conceituais. Considera-se a abrangência de escalas assim como o conhecimento da história do paisagismo brasileiro, dos aspectos tecnológicos, do projeto e planejamento da paisagem. Pode-se listar algumas competências esperadas. (SILVA, 2005): 


\section{Aspectos Históricos}

- entendimento dos contextos históricos e sociais do mundo e, principalmente, do nosso país para a compreensão e a identificação dos agentes sociais de transformação da paisagem;

- entendimento da evolução do espaço livre de edificação e do espaço livre de urbanização, suas ideologias e formas;

- entendimento das políticas públicas e dos sistemas de espaços livres urbanos.

\section{Aspectos Tecnológicos}

- entendimento dos conceitos das disciplinas de: movimentos de terra, drenagem, iluminação pública, análise de solos, análise climática, geoprocessamento, recursos hídricos e demais conceitos pertinentes a disciplina;

- entendimento dos ecossistemas, da vegetação nativa brasileira e da manutenção dos sistemas faunísticos;

- capacitação para o entendimento das implicações técnicas relacionadas ao plano de manejo de áreas ambientalmente estratégicas.

\section{Aspectos do Projeto e Planejamento da Paisagem}

- capacitação para o entendimento de todas as escalas de abordagem, do pequeno jardim ao planejamento de cidades e regiões;

- capacitação para a concepção espacial das áreas livres de edificação e das áreas livres de urbanização;

- capacidade de representação gráfica para expressar e conceber.

\section{Legislação Ambiental}

- conhecimento da legislação ambiental e de suas implicações socioeconômicas na espacialização sobre o território.

No estabelecimento de conteúdos, cabe questionar: quais são os conceitos-chave para o entendimento da paisagem, do urbanismo e da arquitetura? quais são os procedimentos e atitudes necessários para facilitar o encaminhamento do aluno ao conhecimento?

A experiência apresentada neste artigo considera as características específicas da aprendizagem do arquiteto em ateliê, levantadas por Donald Schön (2000), segundo o qual o "aprender na ação" se torna cotidiano da graduação e da vida profissional.

Cabe ao arquiteto urbanista conhecer os processos históricos, socioculturais e econômicos que transformam o território. As disciplinas de Paisagismo e de Planejamento Urbano e Regional, assim como tantas outras dentro do curso, possuem papel relevante na formação desse ator social que trabalha com a paisagem, seja concebendo um projeto de edifício, um jardim, um conjunto habitacional, uma intervenção urbana, um parque, um sistema de transporte, seja planejando uma cidade ou região. 
Portanto, o arquiteto urbanista não pode se ater a uma formação técnica e competente que vise, apressadamente, a atender a demanda do mercado de trabalho, fato que historicamente modelou o ensino superior no Brasil. (SANTOS, 2002; WARDE, 2000). É necessário avançar, ir além, fazer do ensino um meio para a formação de cidadãos que saibam responder aos conflitos gerados por interesses contraditórios de diferentes grupos sociais.

O entendimento da abrangência desejada para a formação do arquiteto urbanista é fruto da construção histórica que se inicia com o decreto de 1933, que institui a profissão no Brasil. É também reafirmado na legislação brasileira em várias ocasiões. Em 1970, após o Encontro de Peritos em Ensino de Arquitetura, organizado pela Organização das Nações Unidas para a Educação, a Ciência e a Cultura (UNESCO), em Zurique, onde estiveram presentes treze países de todos os continentes, Vilanova Artigas (2004, p. 86-91) proferiu uma palestra no Instituto dos Arquitetos do Brasil - Departamento São Paulo (IAB-SP), na qual relatou um resumo das discussões ocorridas no encontro:

A partir da noção de projeto enquanto design, o arquiteto, desde sua atuação pelo desenho industrial, através da programação visual e como construtor da paisagem, terá uma responsabilidade maior. É preciso, então, formar, a partir das escolas, um tipo de homem novo, o arquiteto novo, voltados para uma conjuntura que não seja mais aquela de caráter semi-renascentista, que faria de nós uma espécie de pseudópodes da indústria de construção, ou quando muito de construtores de monumentos. [...] Quando nós colocamos na frente do planejamento, [...] por um tipo de planejamento que visse a cidade como produto do desenvolvimento tecnológico, a cidade como fato industrial do mundo contemporâneo, como cidade industrial. Aí o planejamento não seria mais o planejamento da cidade ou região isolada nas suas conjunturas, mas a consideração do que se poderia chamar de 'o universo do environnement'. Ou seja, o universo do meio ambiente.

A necessidade de uma formação diferenciada para entender não apenas o edifício, mas a paisagem e os processos de ocupação territorial era então percebida e debatida. Também já se percebia que as condições específicas de cada país deveriam ser consideradas desenhando diferentes estruturas, conforme a necessidade e realidade socioeconômica, como coloca Artigas (2004, p. 89):

É certo que poderíamos perguntar: mas, para os três tipos de países que lá estiveram, as escolas podem ser as mesmas? [...] Evidente que não. É que se há um ideal universal de que tipo de formação deva ter o arquiteto, então a formação dos quadros universais para esse processo encontra dificuldades enormes.

Não é possível discutir conteúdos sem considerar as especificidades do arquiteto e urbanista brasileiro. Deve-se considerar suas atribuições legais e seu papel social no desenvolvimento da sua prática profissional. 
Vive-se uma crise generalizada do ensino superior junto a uma crise específica do ensino de arquitetura e urbanismo, sendo o momento propício para rever o papel social do arquiteto urbanista brasileiro e, assim, discutir os conteúdos necessários para a sua formação.

\section{OBJETIVOS}

Por meio da sistematização e apresentação da experiência pedagógica desenvolvida na disciplina de Planejamento Urbano e Regional A, na PUC-Campinas, entre os anos de 2009 e 2012, objetiva-se aqui a construção de diálogos interdisciplinares, que explicitem avanços no planejamento e na estruturação territorial à medida que se considera o sistema de espaços livres de edificação.

Busca-se, com o exercício proposto, identificar e questionar os processos contemporâneos de ocupação territorial, condicionados por uma lógica em que o transporte individual é dominante e pela ausência de estruturação territorial prévia aos projetos de parcelamento de solo.

A disciplina não se limita a preparar o aluno para a prática profissional, mas busca potencializar uma prática reflexiva baseada na construção de argumentos que se revelam em desenhos, considerando as diferentes escalas, os interesses de diferentes agentes, as contradições existentes e a história da cidade. $O$ desenho da paisagem é utilizado aqui como instrumento de reflexão que contesta a realidade e cria argumentos para novas configurações espaciais urbanas.

\section{JUSTIFICATIVA}

Argumenta-se a favor da tese que julga conveniente extrair da realidade local propostas para a condução da educação da sociedade brasileira. $O$ ensino de arquitetura e urbanismo vem se transformando rapidamente nos últimos trinta anos, na busca de compreender as formas de ocupação do território induzidas pelas novas dinâmicas socioeconômicas e pelas diferenças sociais. A identificação e o enfrentamento das questões relevantes à realidade regional colaboram para reafirmar as peculiaridades da paisagem nacional.

A compreensão das formas de organização territorial desenvolvida no Brasil depende de estudos de diversas escalas de atuação na paisagem. A prática projetual pode definir um recorte territorial de atuação, porém necessita do entendimento simultâneo das diversas escalas e aspectos.

Entretanto, esse pressuposto encontra-se ameaçado nas escolas de arquitetura e urbanismo ao identificar-se um número representativo de docentes que excluem ou, simplesmente, estão impossibilitados de incluir a questão do território no escopo da disciplina por diferentes razões: alguns pelo tempo escasso, outros por falta de referência quanto à prática pedagógica. 
A questão do território, por meio do planejamento da paisagem e do planejamento regional e urbano, possibilita a seu investigador questionar valores e explicitar consensos e dissensos contidos nas ações tomadas pela sociedade sobre a paisagem, permitindo, dessa maneira, uma formação mais completa e consciente das realidades físicas e socioculturais existentes.

Considerando a realidade da Região Metropolitana de Campinas (RMC) e considerando que a grande maioria dos alunos da PUC-Campinas são oriundos de cidades médias do interior paulista, a disciplina trabalha com o processo de ocupação de novos territórios urbanos. Objetiva-se questionar o processo existente, no qual o projeto de parcelamento de solo na configuração de loteamentos e condomínios desconsidera a estruturação territorial tanto da área já urbanizada como da área objeto do projeto. A disciplina trabalha no sentido de inverter a lógica de ocupação. Primeiro estrutura-se o território considerando recursos naturais, infraestrutura, paisagem e a cidade existente para, posteriormente, desenvolver o projeto de parcelamento do solo. Toma-se como recorte territorial uma bacia hidrográfica parcialmente urbanizada.

Considera-se, nesse processo, a necessidade de conduzir conscientemente a concepção dos espaços, finalidade primeira do arquiteto urbanista, de modo a questionar as hierarquias de valores dominantes em prol da paisagem, do meio ambiente e da busca por uma cidade aberta à igualdade dos sujeitos.

A consciência da realidade física e sociocultural é fundamental para que o arquiteto urbanista conceba os espaços - que podem ter como objeto desde um edifício ou jardim, até um macrozoneamento regional, um plano de manejo de um parque ou um projeto de parcelamento de solo - que respondam e explicitem o QUERER da sociedade.

\section{MÉTODO EMPREGADO}

O método empregado parte da discussão das habilidades e competências desejadas e estabelece procedimentos e posturas que buscam, junto com os alunos, potencializá-las. Acredita-se que a integração entre disciplinas não necessita possuir recortes territoriais idênticos, caminho comumente debatido por docentes. Busca-se a integração disciplinar por meio da construção processual. Para isso é necessário identificar e debater quais seriam essas "habilidades e competências" profissionais a serem desenvolvidas ao longo do curso de graduação de Arquitetura e Urbanismo. Na disciplina de Planejamento Urbano e Regional A da PUC-Campinas, objetiva-se desenvolver as seguintes habilidades e competências por meio dos seguintes procedimentos:

- reconhecimento e significação das escalas de trabalho;

- entendimento das representações cartográficas (relevo, hidrografia, várzeas);

- questionamento dos modelos e arquétipos de cidades;

- estabelecimento de diretrizes de uso e ocupação - utilizando o desenho como elemento indutor; 
- desenvolvimento de intervenções que visem à conexão e transformação do entorno;

- pesquisa de soluções espaciais a partir de premissas e diretrizes adotadas;

- criação de novos modelos de cidade que levem em conta: formas de produção, direito urbanístico e legislação ambiental;

- desenvolvimento do parcelamento como processo de valor social onde se estabelecem as relações entre espaço público (institucional e espaços livres de edificação) e espaço privado;

- significação do conceito de densidade;

- estudos tipológicos viários, de espaço público e edifícios;

- desenvolvimento de habilidades de relacionamento pessoal para a condução de trabalhos em equipes interdisciplinares.

O curso é subdividido em três etapas: leitura territorial, estruturação do território e projeto de parcelamento do solo. A cada etapa correspondem aulas expositivas, exercícios e apresentação de um produto gráfico. $\bigcirc$ exercício considera a cidade existente, entretanto, busca romper com a sua lógica de crescimento questionando a mobilidade, a densidade e os graus de centralidades existentes.

Na segunda etapa, propõe-se como temas a serem trabalhados: sistema viário, modalidade de transporte, sistema de espaços livres, graus de centralidade e densidades desejadas. Busca-se construir uma estrutura do território como resultado de um planejamento que envolva o relevo e a cidade existente, a preservação de áreas destinadas a parques e áreas de interesse ambiental, assim como as grandes conexões viárias e de transporte público, considerando o relevo e a cidade existente.

Na terceira etapa, desenvolve-se um projeto de parcelamento de solo em que é trabalhado o conceito de centralidade de bairro, contrapondo com as densidades desejadas. Constrói-se a noção de "centralidade induzida", na qual os espaços livres de edificação e as áreas institucionais aliadas ao sistema viário e de transporte público são elementos a serem considerados pelo desenho. A noção de centralidade induzida pressupõe que o zoneamento não é o único instrumento que induz usos e formas de ocupações. A separação de atividades é tomada como decorrente da experimentação e do encontro da justa distância entre as diferentes funções segundo o grau de compatibilidade e incompatibilidade. Busca-se construir a percepção de que os espaços públicos, sejam livres de edificação (vias, praças, parques) ou edificados (áreas institucionais), podem induzir a localização de comércio e serviços, de forma a privilegiar as centralidades de bairro, o comércio de rua, o caminhar, em contraposição ao binômio automóvel e shopping center.

Como apoio a cada etapa são desenvolvidos "exercícios de pesquisa e experimentação" relacionados às leituras e dinâmicas propostas, que possuem como objetivo transformar conceitos em referências espaciais. Busca-se problematizar as questões: qual é a cidade que queremos? quais foram as contribuições da disciplina (ou das disciplinas?) de Urbanismo e Paisagismo para as cidades que conhecemos hoje? 
Por meio da leitura da Carta de Atenas, de novembro de 1933, e do livro de Jane Jacobs, lançado em 1961 e intitulado Morte e vida de grandes cidades (JACOBS, 2001), busca-se construir um debate que incorpore elementos da cidade modernista e da cidade contemporânea.

Nos primeiros semestres em que trabalhamos com os dois textos, percebeu-se grande dificuldade dos alunos em assimilar conteúdos e argumentações da cidade modernista ou dos valores físicos espaciais preconizados por Janes Jacobs.

O "exercício de pesquisa e experimentação", proposto com base nos textos, contribuiu para a construção desse conhecimento. Propôs-se que cada equipe preparasse dois painéis compostos por: imagens aéreas contendo a quadra tipo, conjunto de quadras-tipo; seção tipo da quadra e fotos da altura do observador. Cada painel deveria revelar os aspectos espaciais da cidade modernista ou da cidade tradicional valorizados por Jane Jacobs. Solicitou-se ainda que fossem explicitados, através de um pequeno texto, os aspectos que esclareciam a pertinência daquele espaço em relação aos conceitos de cidade modernista ou de cidade tradicional.

Com esse exercício, foi possível construir um repertório comum, partilhado com toda a classe, de mais de dez cidades ou trechos de cidades onde foram identificados os aspectos físicos espaciais da cidade tradicional e da modernista. Após a construção desse repertório, foi possível avançar no debate referente às características da cidade contemporânea.

Outro "exercício de pesquisa e experimentação" que desenvolvemos foi uma dinâmica em que os alunos assumem ser um tipo de uso do solo - espaço livre (parques), habitacional (alta renda, renda média e baixa renda), comércio, indústria, áreas institucionais - e a sala de aula transforma-se num teatro onde o palco passa a ser 0 território a ser ocupado. $\bigcirc$ diretor da dinâmica é um docente que convida cada grupo a se localizar e, por meio de questionamentos e mudanças de diretrizes, solicita que cada um se posicione segundo seu interesse. A dinâmica ajuda a entender as disputas e contradições urbanas, assim como, segundo os alunos consultados a posteriori, ajuda no entendimento da noção de "centralidade induzida".
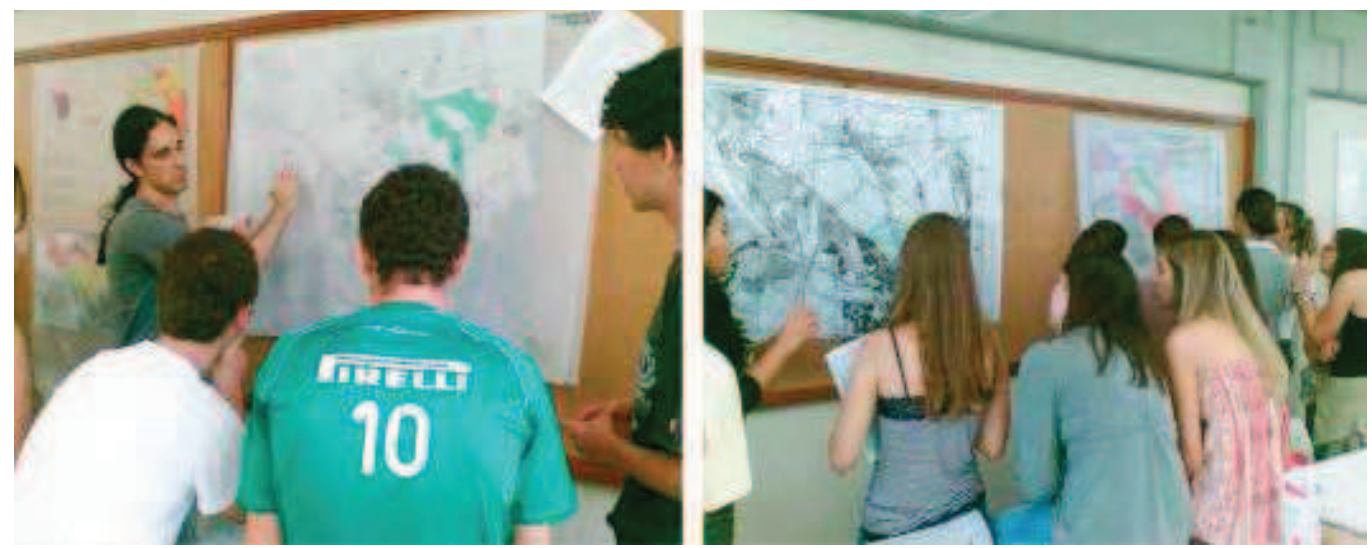

Figura 1 Processo de avaliação.

Fonte: Autores. 
Outro ponto importante do método são as posturas construídas frente à avaliação. Acredita-se que esta é um dos pontos essenciais para o processo de aprendizagem. Independente da formalidade com que é tratada, a avaliação está sempre presente no processo de aquisição de conhecimento. Sob esse aspecto, a avaliação possui caráter positivo, constituindo-se em um momento no qual é passível de ser feita a síntese de todo o processo de trabalho. Nesse sentido, a avaliação passa a ser um instante importante do processo, contrapondo-se a um simples julgamento unilateral. A aprendizagem e a avaliação incluem:

- presença e participação do aluno nos trabalhos de grupo;

- presença e participação nos seminários;

- participação nos momentos de avaliação coletiva.

Para a construção junto ao grupo de alunos da noção de que a aprendizagem se dá ao longo dos processos de análise, proposição e avaliação é necessário que o debate seja promovido constantemente. As oito horas-aula contínuas contribuem para a eficiência desse método. Nos últimos 60 minutos de cada aula, os desenhos ainda em desenvolvimento são colocados na parede e as dúvidas e avanços são apontados e discutidos coletivamente.

No dia da avaliação de cada etapa, os trabalhos são colocados novamente na parede e avaliados por alunos e professores. Uma grande tabela desenhada no quadro branco explicita os critérios de avaliação e os resultados obtidos - em forma de nota ou anotações gráficas. Também é ali explicitada a avaliação dos colegas, que apontam os três melhores trabalhos e entregam uma ficha com a argumentação e justificativa da escolha. Tal procedimento ajuda o aluno a refletir sobre o trabalho do colega e perceber dificuldades e avanços nos diferentes trabalhos. $O$ procedimento de avaliação explicita a capacidade de compreender os bons resultados e os seus próprios entraves.

\section{RESULTADOS OBTIDOS}

\subsection{ETAPA 1}

Na primeira etapa, os alunos desempenham o papel de órgão municipal de planejamento na definição de diretrizes de uso e ocupação do solo da área de estudo (produto). Desenvolvem-se exercícios e atividades voltados:

- ao entendimento físico da "região" e da área de estudo (sub-bacia);

- à análise das diretrizes municipais de planejamento já existentes;

- às condições de infra e superestrutura disponíveis na área e em seu entorno;

- à produção de diretrizes de uso e ocupação do solo e de investimentos do poder público, levando em conta o planejamento municipal e as potencialidades e limitações da área. 


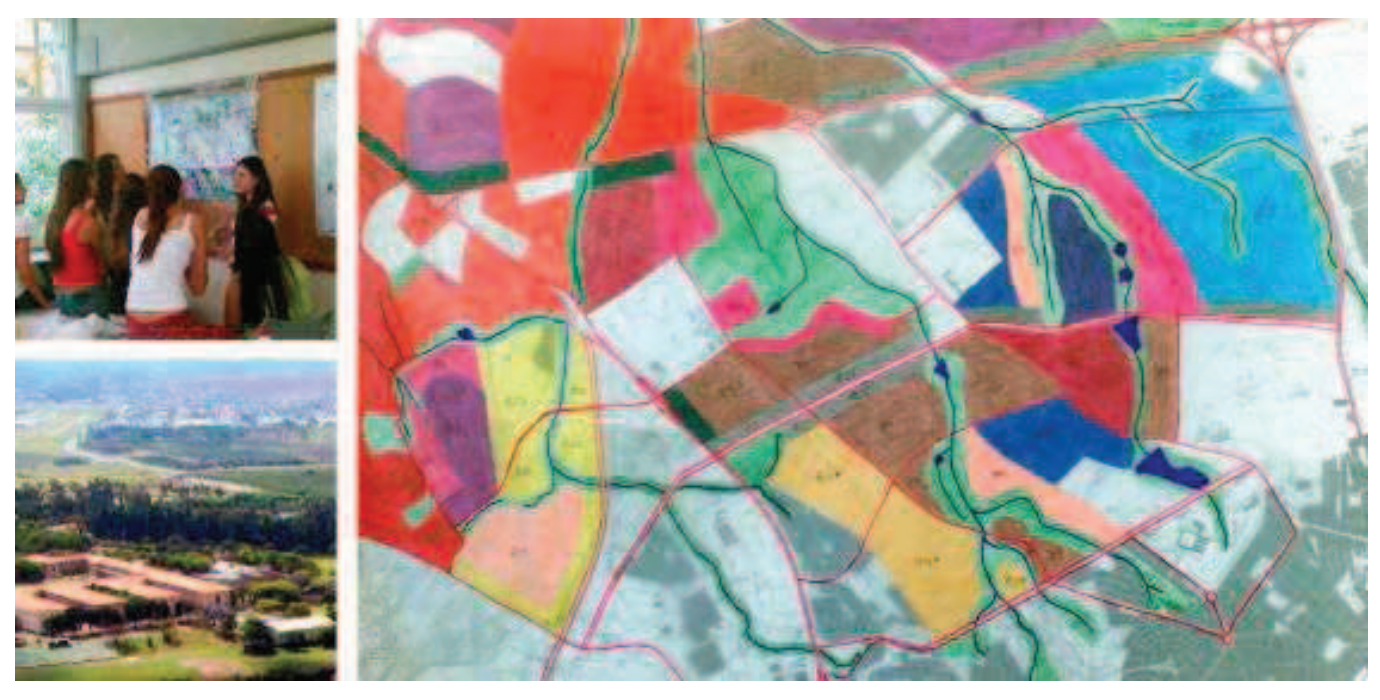

Figura 2 Etapa 1 - Leitura Territorial: aspectos físico-espaciais. Fonte: Autores e trabalhos dos alunos de PUR-A de 2009 e 2010.

Esta etapa busca construir a compreensão físico-espacial referente ao recorte territorial definido pela disciplina, por meio da:

- leitura da carta técnica que indica: relevo, rede hídrica, áreas de várzea, áreas de mata, parcelamentos planejados, executados e consolidados;

- leitura dos planos e projetos existentes para o objeto de trabalho;

- visita ao local.

Cabe salientar que a visita ao local foi testada em diferentes momentos do desenvolvimento da etapa de leitura territorial. Baseado nos diferentes resultados obtidos, pode-se afirmar que a visita de campo se torna mais eficiente quando o aluno já fez um esforço para entender o local estudado por meio das representações gráficas, dos planos e projetos existentes. É conveniente, ainda, que os alunos tenham desenvolvido, de forma preliminar, alguns argumentos de estruturação da área. Dessa forma a visita de campo é vista como oportunidade de confirmar ou impor revisões às argumentações até ali construídas.

\subsection{ETAPA 2}

Na segunda etapa, definem-se as áreas prioritárias de ocupação e expansão da mancha urbana, considerando as propostas de: elementos de grande porte do sistema de espaços livres, estrutura viária principal, estrutura de transporte, localização de centralidades de médio porte.

Esta fase tem como objetivo desenvolver a habilidade de relacionar diferentes escalas e ganhar maior domínio sobre cada escala trabalhada, assim como perceber os elementos que estruturam o território. 


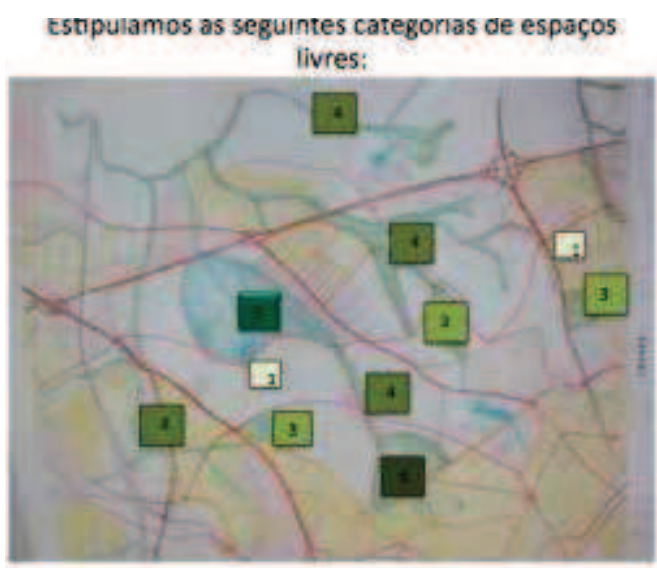

2 PAAÇA QUADRA. Carater de centralidade local.

3 PRAÇA BAIRRO Carater de centralidade local.

4. PAgQue LINEAh. Carater de centralidade local.

PARque RECreativo. Corbter de centralidade que polariza a area e a cicade.

PARQUE RECREATIVO E DE

PRESIRVACAOO Carźter de centralicade Que polariza a áres e a cidade.

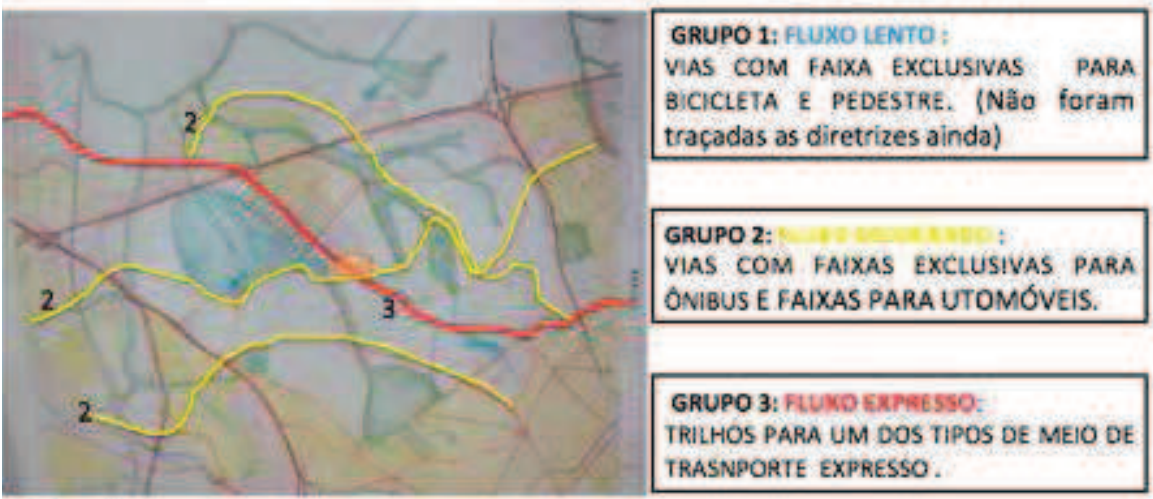

DOSSlVEL AREA DESTINADA AO TERMINAL INTEMMODAL

Figura 3 Etapa 2 - Estruturação Territorial.

Fonte: Autores e trabalhos dos alunos de PUR-A de 2009.

\subsection{ETAPA 3}

Na terceira etapa, trabalha-se com um setor (gleba) escolhido que deverá ser parcelado. Apresentam-se os critérios e as circunstâncias que precederam a Lei Federal n. 6.766/79, suas alterações em 1999, e faz-se uma rápida introdução sobre as questões debatidas no PL 3057 - Lei de Responsabilidade Territorial. Entretanto, o principal objetivo é problematizar a questão urbana e levantar outra: qual é a cidade que queremos?
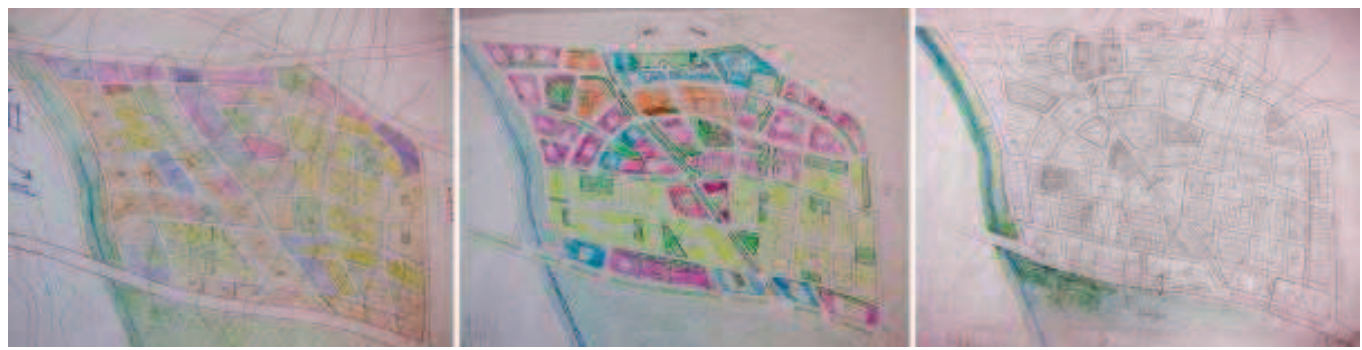

Figura 4 Etapa 3 - Projeto de Parcelamento do Solo: densidade e centralidade induzida.

Varias versões de um mesmo trabalho.

Fonte: Autores e trabalhos dos alunos de PUR-A de 2009. 
Esta etapa busca desenvolver o domínio da escala de projeto urbano e dos conceitos de densidade e "centralidade induzida", além de promover uma pesquisa por tipos viários e edilícios na definição de um plano de massa, com gabaritos, usos, desenho de quadras e lotes.

\section{CONSIDERAÇÕES FINAIS}

Os métodos e procedimentos aqui explicitados estão em processo de construção. Os professores da disciplina Planejamento Urbano e Regional A da PUC-Campinas buscam avançar na construção de habilidades e competências, convidando os alunos a refletirem sobre a realidade na qual estão inseridos. Objetiva-se formar um cidadão que perceba e reflita sobre as contradições urbanas e se coloque como sujeito capaz de transformar a realidade. Não se trata de uma formação ingênua em que as dificuldades da transformação desejada não sejam explicitadas. Ao contrário, busca-se construir uma habilidade argumentativa que tome o desenho da paisagem como instrumento de contestação da realidade.

\section{REFERÊNCIAS BIBLIOGRÁFICAS}

ARTIGAS, Rosa; LIRA, José Tavares Correia de. Vilanova Artigas: caminhos da Arquitetura. São Paulo: Cosac Naify, 2004, p. 86-91.

COLL, César. Os conteúdos na reforma: ensino e aprendizagem de conceitos, procedimentos e atitudes. Porto Alegre: Artmed, 1998.

JACOBS, Jane. Morte e vida nas grandes cidades. São Paulo: Martins Fontes, 2001.

MORIN, Edgar. Os sete saberes necessários à educação do futuro. Brasília: UNESCO, 2002, p. 32.

SANTOS, Milton. O país distorcido. São Paulo: Publifolha, 2002.

SCHÖN, Donald A. Educando o profissional reflexivo: um novo design para o ensino e a aprendizagem. Porto Alegre: Artmed, 2000, p. 18.

SILVA, Jonathas Magalhães Pereira da. O papel da disciplina de Paisagismo na formação dos Arquitetos Urbanistas. 2005. 256 f. Tese (Doutorado em Estruturas Ambientais Urbanas) - Faculdade de Arquitetura e Urbanismo, Universidade de São, São Paulo, 2005.

WARDE, Mirian Jorge; CARVALHO, Marta Maria Chagas de. Política e cultura na produção da História da Educação no Brasil. Contemporaneidade e Educação. São Paulo, Ano V, n. 7, 2000. 
Jonathas Magalhães Pereira da Silva, Denio Benfatti,

Tomás Antonio Moreira e Caroline Krobath Luz Pera 